intensity? These are but two key experimental points that cross one's mind.

If the experiment does indeed prove successful - and the authors have decided to investigate the "oscillation" between the covalent $\mathrm{NaI}$ and ionic $\mathrm{Na}^{+} \mathrm{I}^{-}$pair of atoms as their test case - it will mark the dawn of an important new era in structural chemistry, one in which the very act of chemical change is charted in the timescale of the process

\section{Seeing flies from space}

\section{John Brady}

THE tsetse fly, transmitter of trypanosome diseases from game to livestock and humans, is a massive blight on life in Africa. The work of Rogers and Randolph, described on page 739 of this issue ${ }^{1}$, by which they demonstrate an effective technique for prediction of areas especially prone to tsetse infestation, introduces a new weapon to Africa's armoury in its attack on the fly.

If the current wars and famines were not enough for the continent to bear, the truly bad news is that Africa's human population of 850 million is increasing in numbers faster than anywhere else in the World; Kenya, for example, will double its present 25 million within the next 20 years. As a result, per capita food production is falling inexorably, by 1-2 per cent a year, so more and more people are feeding on less and less. The starting point of agricultural productivity is low anyway: Africa contains 20 per cent of the world's pasture land, yet raises only 10 per cent of the world's cattle, which yield only 3 per cent of the world's meat and milk.

The socio-economic and ecological causes are complex. But in terms of meat and milk production they revolve around the cow, and thus around the tsetse fly. Indeed, by precluding the use of draught animals for ploughing, transport or manure, the trypanosome diseases it carries kept from tropical Africa the agro-economic revolution that occurred in the Middle East around $4000 \mathrm{BC}$. And the fly exercises the same malign influence today: cattle diseases exclude normal mixed farming from some 10 million $\mathrm{km}^{2}$ (an area 20 times the size of France), and human sleeping sickness still debilitates and kills.

Ever since the link between fly and disease was discovered, affected countries have tried to control both. But the results have been scarcely commensurate with the effort perhaps 5 per cent of the area cleared in 50 years. So the search is on for the means to accelerate the development of effective control measures. With the problems spread on the continental scale, continent-wide solutions need to be found, and this is precisely what Rogers and Randolph have begun to do, with the aid of satellite imagery.

Modern satellites produce data that can be analysed to reveal the ecological condition of itself. The authors have already simulated experimental radial distribution curves for excited $\mathrm{NaI}$ as a function of time. What we now await is the actual experimental determination.

John Meurig Thomas is at the Davy Faraday Research Laboratory, Royal Institution, 21 Albemarle Street, London W1X 4BS, and the University of Wales, University Registry, Cathays Park. Cardiff CF1 3NS, UK. the lands they pass over. Especially useful is the normalized difference vegetation index (NDVI) which, in effect, indicates the level of photosynthetic activity, and thus the vegetation cover $^{2}$. From this can be inferred the levels of recent rainfall. Monthly NDVI images covering the whole of Africa are available ${ }^{3}$, and they reflect in a stunningly impressive way the moving seasonal rainfall as it sweeps to and fro across the continent.

These data have obvious potential for warning of ecological change such as drought ${ }^{4}$, but have also begun to be analysed for what they may indicate of the distribution of animals, through correlations between habitat characteristics and vegetation indices. For instance, on the macro, countrywide scale likely locust breeding zones in Mali have been found; and on the micro scale, individual Landsat pixels have been used to pick out the feeding grounds of waders in the threatened moorlands of northern Scotland. What Rogers and Randolph have done is to use NDVIs to reveal areas of maximum tsetse infestation, aiming to do this soon for the whole continent.

The potential for exploiting NDVIs in disease prediction had been hinted at in work that identified, after the event, periods and areas in Kenya likely to be subject to outbreaks of the mosquito-borne cattle disease, East Coast fever ${ }^{5}$, but this - as with the locusts in Mali - required satellite data concurrent with the outbreaks being predicted. Rogers and Randolph, however, have taken a synoptic view, and reveal that NDVIs averaged over several years in the 1980 s correlate beautifully with long-term surveys of tsetse flies made in the 1970 s and much earlier. Moreover, they have correlated NDVIs with habitat characteristics and animal populations in a rigorous, statistical sense. The authors show not only how the seasonally changing NDVIs across the year relate to each following month's tsetse population (because breeding success depends partly on saturation deficit, which is associated with rainfall), but also how annually averaged NDVIs indicate where - geographically tsetse survival rate will be highest, and hence the risk of trypanosome transmission greatest.

Bearing in mind that the area potentially infested with the fly is covered by only a few hundred tsetse entomologists (say 50,000 $\mathrm{km}^{2}$ per entomologist?), the gaps in our knowledge of tsetse distribution and the consequent trypanosome 'challenge' are - like everything else in the continent - on an epic scale. Rogers and Randolph may have taken a key step in crossing some of those gaps, in that their technique should pin-point areas for control.

For example, there is a large belt of tsetse flies running through the countries south of Malawi. By 1985 Zimbabwe was on the way to ridding itself of its own share of the flies and was looking for the means to prevent reinvasion from its neighbours. It approached the European Community for aid to solve the problem by attacking the whole belt. The EEC was on the point of agreeing to finance aerial spraying of the entire $35,000 \mathrm{~km}^{2}$, when a now infamous full-page article by the late Marcus Linear in The Sunday Times in effect killed the programme, by influencing the Council of Ministers against the use of broadcast insecticide (even though treatment would have been at less than $10 \mathrm{~g} \mathrm{ha}^{-1}$ ).

Although one may question the right of the West's eco-lobby to interfere in the Third World's solutions to its own desperate problems, there was one happy result from the ensuing delay: a more environmentally friendly technology caught up with the aeroplanes, and simple traps will now be used instead of aerial spraying.

These traps (or, more properly targets) were developed in Zimbabwe by G. A. Vale and his colleagues. They consist of a rectangle of black cloth on a wire frame baited with key components of cow odour and doped with a quick-acting, pyrethroid insecticide. Tsetse flies are irresistibly attracted upwind by the smell, see the black target and - perhaps taking it for a cow - fatally land on it. So effective are the targets that by using them alone (at a mere $4 \mathrm{~km}^{-2}$ ) Vale succeeded within 6 months in exterminating all tsetse from a $600 \mathrm{~km}^{2}$ trial area in Zimbabwe ${ }^{6}$.

So now the EEC programme will use targets. Compared to the bulldozing technique of aerial spraying, this is like using a stiletto, and demands the stiletto's precise handling: targets work well only when sited with great care. Hence Rogers and Randolph's method of identifying high infestation zones will provide an important way of helping to optimize the distribution of targets over the vast areas in which it is now planned to site them.

John Brady is in the Department of Biology, Imperial College, Silwood Park, Ascot, Berkshire SL5 7PY, UK.

\footnotetext{
Rogers, D. J. \& Randolph, S. E. Nature 351, 739-741 1991).

Sellers, P. J. Int. J. Rem. Sens. 6, 1335-1372(1985)

3. Tucker, C. J., Townshend, J. R. G. \& Goff, T. E. Science 227. 369-375 (1985).

4. Henricksen, B. L. \& Durkin, J. W. Int. J. Rem. Sens. 7, 1583. 1608 (1986)

5. Linthicum, K. J., Bailey, C. L., Davies, F. G. \& Tucker, C. J. Science 235, 1656-1659 (1987).

6. Vale, G. A., Lovemore, D. F., Flint, S. \& Cockbill, G. F. Bull. ent. Res. 78, 31-49 (1988)
} 